\title{
VIBRATION ACTIVATORS IN THE CONSTRUCTION TECHNOLOGY
}

\author{
Victor Kuzmichev ${ }^{1}$, Vladimir Verstov ${ }^{2}$ \\ ${ }^{1}$ Peter the Great Saint Petersburg Polytechnic University, \\ Polytechnicheskaya ul. 29, St. Petersburg, 195251, Russia \\ ${ }^{2}$ Saint Petersburg State University of Architecture and Civil Engineering, \\ Vtoraja Krasnoarmejskaja ul. 4, St. Petersburg, 190005, Russia. \\ ${ }^{1}$ kuzmichev_va@mail.ru, $25750195 @$ mail.ru
}

\begin{abstract}
The paper covers designing methods of original structures for vibration activators on the basis of balanced eccentric vibration exciters, which can be used in designs of mixers, feeders and other processing equipment in order to increase intensity and effectiveness of their work. Regularity of the oscillation amplitude, providing stable intensive vibration effect on the processed material, regardless of its structural and rheological properties (size distribution, binder type, etc.), in combination with the constant frequency is a well-known advantage of these vibration activators.

The distinctive advantage of the considered vibration exciters from the point of view of machine vibration isolation is a balance of oscillating masses and, as a consequence, reduction of dynamic loads on external objects. The paper presents description of the design; the process of interaction with the treated medium revealing the following property of the balanced eccentric vibration activators: static (dynamic) balancing of the system, set in the air medium, is not affected when dipping the vibration activator into the mix.

The paper presents methods of balancing adjustment of vibration activators at the design stage and examples of calculations.
\end{abstract}

\section{Keywords}

Vibration exciter, kinematic excitation of oscillations, design technology, dynamic balance.

\section{Introduction}

Development of vibration technology is characterized by appearance of vibration machines for different purposes and application design. A variety of types and modifications of vibration machines, as well as conditions of their use provide a number of specific requirements to their principal design, structural execution and performance of their drives - vibration exciters (Belokobyl'skiy et al., 2008; Bauman and Bykhovskiy, 1977; Verstov, et al., 2013; Chelomey, 1981a; Den-Gartog, 1960; Emel'yanova et al., 2009; Blekhman, 1994).

Types of vibration exciters (vibrators) are divided into four main groups by their construction design: inertial (unbalanced, centrifugal), crank mechanisms (excen- tric), electromagnetic and reciprocating (pneumatic and hydraulic) (Efremov and Lobanov, 2008; Efremov et al., 2011a; Efremov et al., 2011b; Kuzmichev, 2013; Efremov and Lobanov, 2009).

It is reasonable to use the method of internal vibration protection of an object, allowing reduction of the level of vibration on the environment, on the one hand, and maximization of vibration effect on the treated material, on the other hand, during the design of vibrating machines and equipment.

Below we consider designs and methods of designing of balanced excentric vibration activators, hereinafter referred to as vibration exciters, in which forced vibrations are carried out due to a flat rotational kinematic pair ex- 
ecuted as an elbow (a crank or an excentric sleeve), as shown in Figure 1.



Figure 1. Excentric kinematic pair. 1 - crank; 2 - body

Excentric vibration exciters are referred to vibration exciters with kinematic excitation of vibrations.

Regularity of the oscillation amplitude, providing stable intensive vibration effect on the processed material, regardless of its structural and rheological properties (size distribution, binder type, etc.), in combination with the constant frequency is a well-known advantage of these vibration exciters.

The distinctive advantage of the considered vibration exciters from the point of view of machine vibration isolation is a balance of oscillating masses and, as a consequence, reduction of dynamic loads on external objects (drive, body, operating personnel, engineering structures, etc.).

\section{Design description}

The design of the vibration exciter includes the following main parts: bearing drive crankshaft installed on main bearings; the body fixed on rod bearings installed via excentric sleeves on the main drive shaft and balances to ensure a dynamic balance (Romanovskiy, 2010; Serebrennikov and Kuzmichev, 1999; Kuzmichev and Lyalinov, 2015; Banfill, 2011). 2.

The flow diagram of vibration exciters is given in Figure

The body of an excentric vibration exciter performs a complex rotational motion consisting of a displaceable mo- tion formed with rotation of the crankshaft around axis $X$ and relative rotation around symmetry $X 1$. If axes $X$ and $\mathrm{X} 1$ of displaceable and relative rotations are parallel, then the movement of the vibrator can be called plane-parallel. If symmetry axis $\mathrm{X} 1$ intersects $\mathrm{X}$ axis in the point "O", then the motion of the vibrator is called precessing. The body of such exciters, hereinafter called precessing, makes motions during the rotation of the crankshaft, which is called a regular precession with nutation angle $B$.

Unlike gyroscopes, the angular rate of rotation of the excentric exciter body around symmetry axis X1 is substantially less that the angular rate of rotation around axis $\mathrm{X}$.

Bearings are considered to be main (1), if axis $X$ of the crankshaft rotation passes through its center; bearings are considered to be rod (2) if they are installed along axis $\mathrm{X} 1$ of the relative rotation of the vibrator. We will consider a vibration exciter to be inboard if the oscillating weight mounted on connecting rod bearings is located between the main bearings (Figure 2a), and to be console, if the oscillating weight is situated behind one of the extreme main bearings (Figure $2 b, c$ ). The following variants are possible during designing: oscillating gravity center is located between the connecting rod bearings or behind the extreme crank bearing. Precessing type console vibration exciters are reasonable to be designed three-point. In this case the connecting rod bearing is situated at the point of application of the inertia resultant of centrifugal forces, and the second support executed as a resilient element is located between the main bearings (Figure $2 \mathrm{~d}$ ).

Static unbalance is typical of plane-parallel type vibration exciters, and dynamic unbalance is typical for precessing type vibration exciters. The balance (static or dynamic) implies a state of the vibration exciter as a technical system in the process, in which the reaction of main bearings against centrifugal forces and moments equals to zero, i.e. the degree of transmission of dynamic loads onto supporting pillars, the foundation and the drive, is rather small. a)
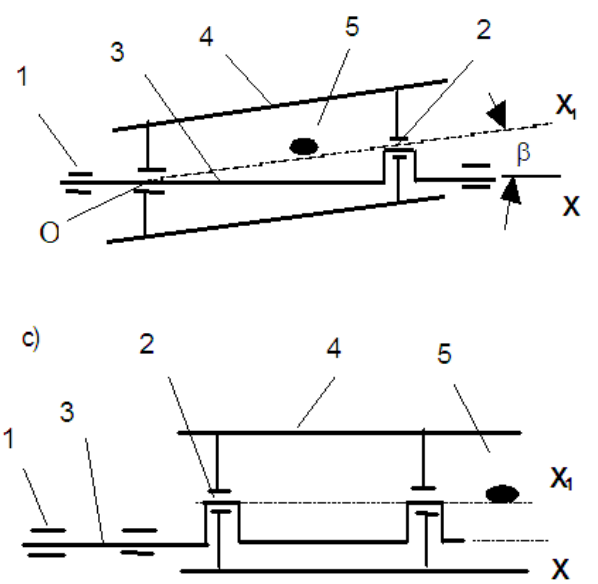
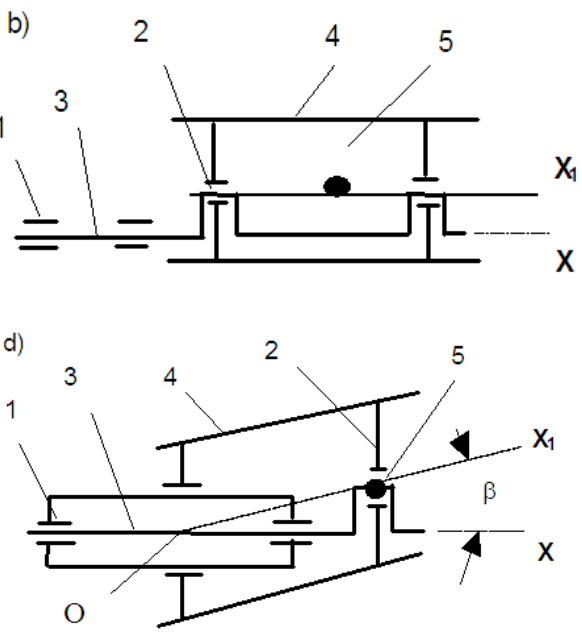

Figure 2. Schemes of typical vibration exciters: a) inboard, precessing, four-point; b, c) console, plane-parallel, four-point; d) console, precessing, three-point. 1 - main bearings, 2 - rod bearings, 3 - drive shaft, 4 - vibration exciter body, 5 - center of oscillating mass gravity. $\mathrm{X}$ is an axis of vibration exciter rotation; $\mathrm{X} 1$ is the main central axis of the exciter body inertia 
It is completely impossible to eliminate the imbalance in actual design of exciters. Therefore, it can be assumed with sufficient practical accuracy that the imbalance ratio equaling the ratio of maximum centrifugal loads in crank bearing 1 to its value in connecting rod bearing 2 should be $0.01 \ldots 0.02$. However, it is rather difficult to determine the unbalance ratio when designing, taken all errors of geometrical dimensions and material density during manufacturing of exciter parts. Therefore, the permissible unbalance can be determined by the highest amplitude of oscillation of the vibration machine body (frame). The value of the body oscillation amplitude is determined by the constraint $A \omega^{2} \leq 0.5 \mathrm{~g}$, where $\omega, A$ is the frequency and amplitude of vibrations of the vibration machine body (frame), respectively.

\section{Methods}

Let us consider the work of a vibration exciter in the medium (Figure 3).

The exciter shaft rotates at a constant angular rate of the motor. Torque occurring on the exciter shaft is a sum of the moments of internal forces (friction in bearings, seals, etc.) and the moment of external forces $M=e P_{c}$.
$P$ is a driving force applied to the connecting rod bearing, which is equal to $M / e$ and directed at the angle of 90 degrees to the crank; $Q$ is a centrifugal force directed along the crank; $P_{\text {c }}$ is the power of the medium resistance which is also applied to connecting rod bearings and is rotated by 90 degrees clockwise with respect to the centrifugal force.

In order to achieve static (dynamic) balance of the system, i.e. when reactions in main bearings 1 equal zero, it is necessary that the sum of all external forces acting in connecting rod bearing (bearings) 2 would equal to zero. It is obvious that the driving force $P$ equals to the power of the medium resistance $P$ in value and is opposite in sign. To balance the centrifugal force $Q$ it is necessary to place counterweights, creating an opposite directed force equal in value. The above said can be written in the form of a constraint:

$$
P=P_{c} ; Q=P
$$

The constraint (1) reveals the following property of excentric balanced vibration exciters: static (dynamic) balancing of the system, carried out in the air, is not affected when dipping the exciter into the mix.

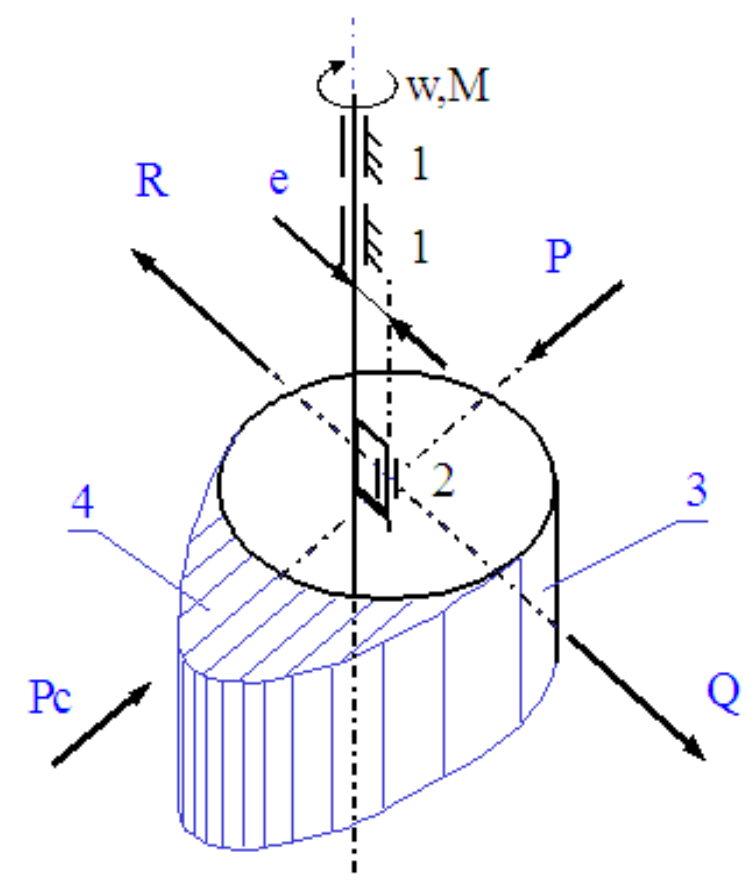

Figure 3. Scheme of driving forces acting on the vibration exciter, dipped in the mix: 1, 2, 3 - the main and connecting rod bearings, as well as the exciter body, respectively; 4 - diagram of the drag force of the medium; $M$ is an external force moment (on the drive shaft); $e$ is excentricity (oscillation amplitude); $Q$ is a centrifugal force produced by the rotation of unbalanced masses; $R$ is a centrifugal force produced by the rotation of a counterweight; $P$ is a driving force applied to the connecting rod bearing; $P_{c}$ is resistance force of the mix (the force preventing rotation of the exciter in the medium); $w$ is the drive shaft rotation rate 


\section{Method of vibration exciter balancing}

The vibration activator balancing method is based on the known positions of rotors balancing, which always can be brought into a state of dynamic equilibrium with two corrective masses arranged in two unspecified correction planes (Chelomey, 1981b).

The calculation task includes the following:

1. determination of the value and location of the resultant of centrifugal forces generated by rotation of unbalanced (fluctuating) masses;

2. determination of the counterweight mass and places of their location on the main drive shaft providing static (dynamic) balancing the unbalanced masses.

Unbalanced weight is the total mass of vibrating elements in the design of a vibration exciter, the center of gravity of which is located on main central inertia axis $X_{1}$.

When calculating according to item 1 it is recommended not to include the weight of the connecting rod bearing assemblies in the unbalanced mass in order to simplify the design process and reduce the calculation procedure.

\section{Calculation according to Item 1.}

Unbalanced mass of the vibration exciter can be represented as a sum of linear distributed and concentrated lengthwise masses.

The most common (possible) typical schemes for precessing exciters are presented in Figures $4 a, b, c, d, e, f, g$. Resultants of centrifugal forces arising as a result of circular body vibrations are defined by the following formulas for typical schemes presented in Figure 4:

$Q_{i}=\int_{\ell} d Q_{i}=\int_{\ell} \omega^{2} q_{i}(\operatorname{tg} \beta) x d x$

where $d Q_{i}$ is a prime centrifugal force.

After substitution of the values of distributed loads into the equation (2) and their integration within appropriate limits we will obtain the following:

a) $q_{i}=$ const $; Q_{1}=\omega^{2} q_{1} g \beta \int_{0}^{l} x d x=\frac{1}{2} \omega^{2} q_{1} l^{2} g \beta$

b) $q_{2}=$ const $Q_{2}=\omega^{2} q_{2} g \beta \int_{l_{1}}^{l} x d x=\frac{1}{2} \omega^{2} q_{2}\left(l^{2}-l_{1}^{2}\right) g \beta$

c) $q_{3}=q^{*}\left(1-\frac{x}{l}\right)$

$Q_{3}=\omega^{2} q^{*} \operatorname{tg} \beta \int_{0}^{l}\left(1-\frac{x}{l}\right) x d x=\frac{1}{6} \omega^{2} q^{*} l^{2} \operatorname{tg} \beta$

d) $q_{4}=q^{*}\left(1-\frac{x-l_{1}}{l-l_{1}}\right)$
$Q_{4}=\omega^{2} q^{*} g \beta \int_{l_{1}}^{l}\left(1-\frac{x-l_{1}}{l-l_{1}}\right) x d x=$

$=\frac{1}{6} \omega^{2} q^{*}\left(l^{2}+l l_{1}-2 l_{1}^{2}\right) g \beta$

e) $q_{5}=q * \frac{x}{l} \quad Q_{5}=\omega^{2} q * \operatorname{tg} \beta \int_{0}^{l} \frac{x}{l} x d x=\frac{1}{3} \omega^{2} q * l^{2} \operatorname{tg} \beta$

f) $q_{6}=q^{*} \frac{x-l_{1}}{l-l_{1}}$

$Q_{6}=\omega^{2} q^{*} \operatorname{tg} \beta \int_{l_{1}}^{l} \frac{x-l_{1}}{l-l_{1}} x d x=\frac{1}{6} \omega^{2} q^{*}\left(2 l^{2}-l l_{1}-l_{1}^{2}\right) \operatorname{tg} \beta$

g) $Q_{7}=\sum_{i=1}^{n} M_{i} l_{i} \omega^{2} \operatorname{tg} \beta$

Diagrams of centrifugal forces and points of application of their resultants for standard circuits of distributed loads are presented in Figures $5 a, b, c, d, e, f$ (letter designations correspond to the typical schemes in Figure 4).

Coordinate $L_{i}$ of the application points of the resultant of centrifugal forces is determined by the following formulas based on the equation (2):

$L_{i}=\frac{\int_{\ell} d M_{i}}{Q_{i}}=\frac{\int_{\ell} x d Q_{i}}{Q_{i}}=\frac{\int_{\ell} \omega^{2} q_{i}(\operatorname{tg} \beta) x^{2} d x}{Q_{i}}$

where $d M_{i}$ s a prime static moment of centrifugal forces in relation to the point $O$.

After substitution of the values of distributed loads and corresponding centrifugal forces into the equation (3) and their integration within appropriate limits we will obtain the following:

a) $L_{1}=\frac{2}{3} 1$

b) $L_{2}=\frac{2\left(l^{3}-l_{1}^{3}\right)}{3\left(l^{2}-l_{1}^{2}\right)}$

c) $L_{3}=\frac{l}{2}$

d)

$L_{4}=\frac{1}{2} \frac{\left(l^{3}+l^{2} l_{1}+l_{1}{ }^{2}-3 l_{1}^{3}\right)}{\left(l^{2}+l_{1}-2 l_{1}^{2}\right)}$

e) $L_{5}=\frac{3}{4} 1$ 
f) $L_{6}=\frac{1}{2} \frac{\left(3 l^{3}-l l_{1}^{2}-l^{2} l_{1}-l_{1}^{3}\right)}{\left(2 l^{2}-l l_{1}-l_{1}^{2}\right)}$

a)

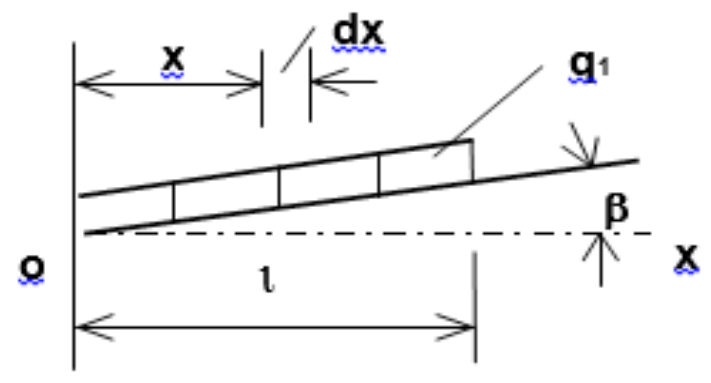

c)

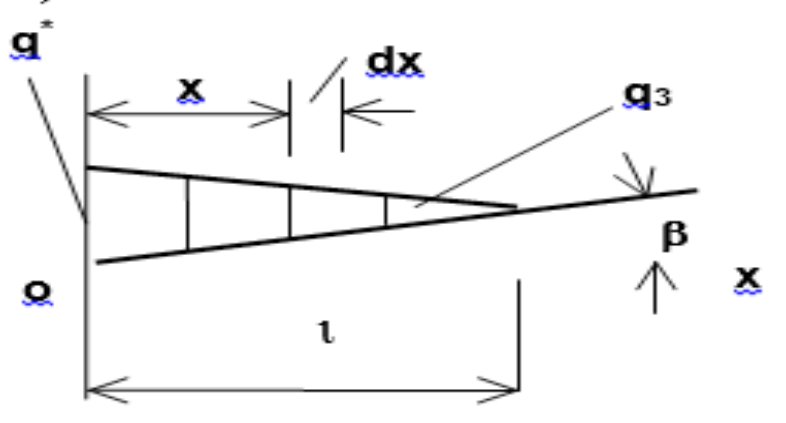

e)

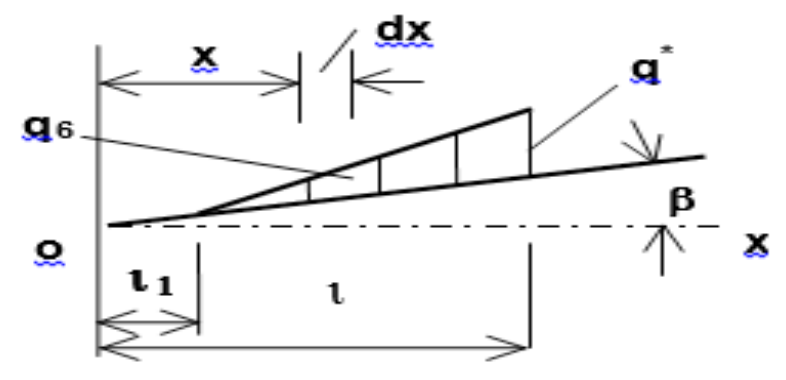

g) $L_{7}=\frac{\sum_{i=1}^{n} M_{i} l_{i}^{2} \omega^{2} \operatorname{tg} \beta}{Q_{7}}$

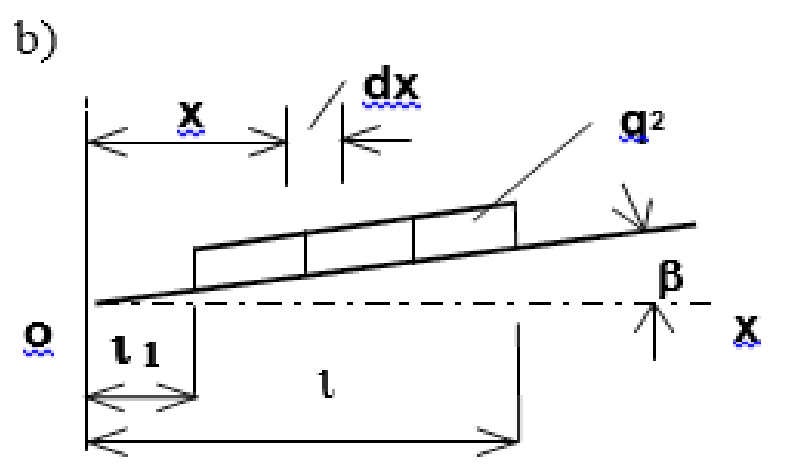

d)

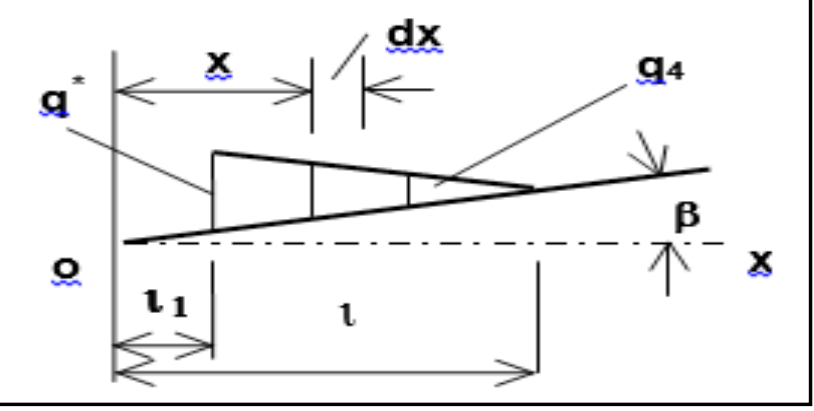

f)

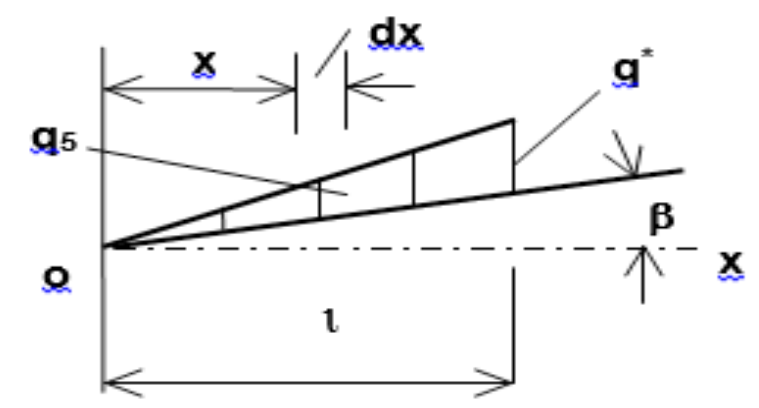

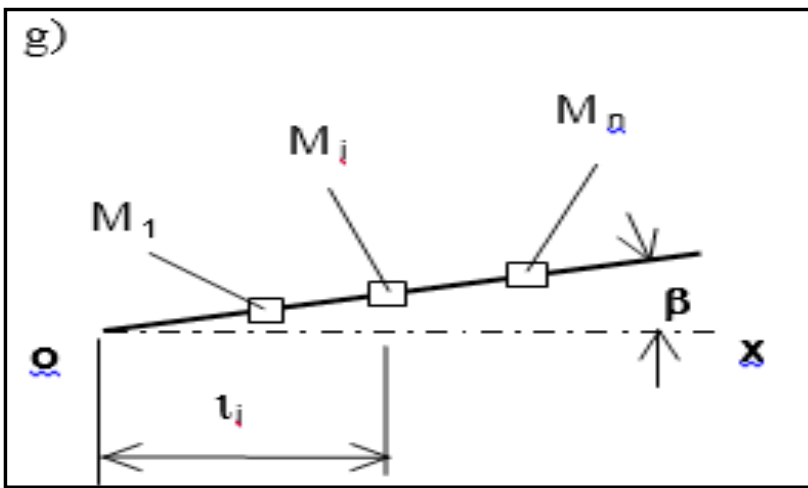

Figure 4. Typical schemes of distributed and concentrated masses: $X$ is the current coordinate; $q_{1}$ is the distributed load; $M_{i}$ is the concentrated mass; / is the length 

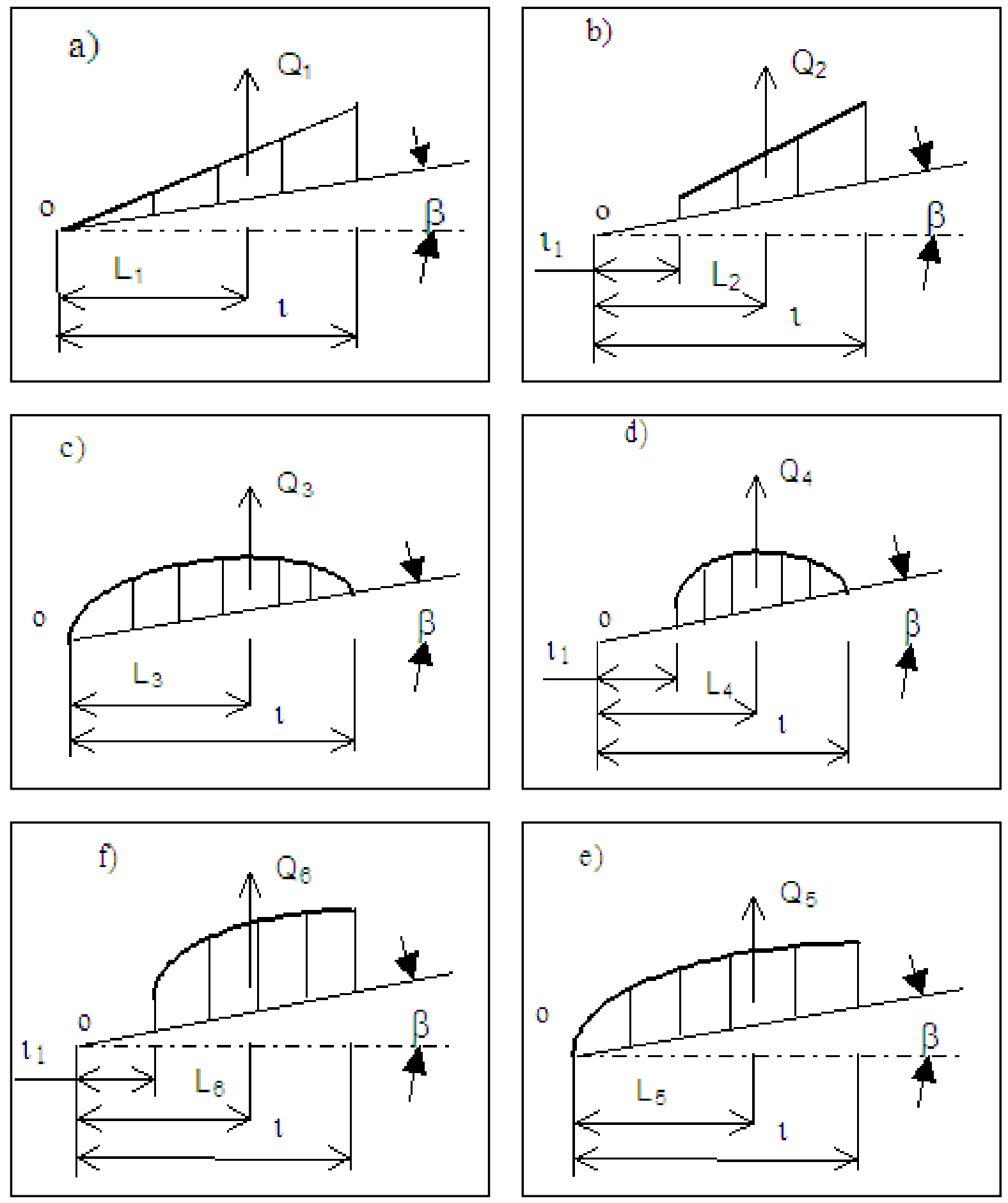

Figure 5. Typical diagrams of centrifugal forces: $Q_{i}$ is a resultant of the centrifugal forces; $L_{i}$ is the distance from the point $O$ to the point of application of the resultant of centrifugal forces 
Example. Let unbalanced exciter body elements be presented in the form of distributed masses $q_{1}$ and $q_{2}$ and concentrated mass $M$ as shown in Figure 6.

When applying the method of superposition (the method of independence of acting forces), resultants of centrifugal forces is determined taking into account the following expressions $(2 a, b, g)$.

$$
Q=Q_{1}+Q_{2}+Q_{7}=\omega^{2} \operatorname{tg} \beta\left(\frac{1}{2} q_{1} l_{1}^{2}+\frac{1}{2} q_{2}\left(l^{2}-l_{1}^{2}\right)+M l\right)
$$

and the point of its implementation (distance $L$ ) is determined considering the following expressions $(3 a, b, g)$ :

$$
\begin{aligned}
& L=\frac{Q_{1} L_{1}+Q_{2} L_{2}+Q_{7} L_{7}}{Q}= \\
& =\frac{\omega^{2} \operatorname{gg} \beta\left(\frac{1}{3} q_{1} l_{1}^{3}+\frac{1}{3} q_{2}\left(l^{3}-l_{1}^{3}\right)+M l^{2}\right)}{Q}
\end{aligned}
$$

Expression (6) is valid on the same basis as the expression (4); here $M_{p}$ is the reduced mass (weight of unbalanced elements of the exciter body modified to the point of the resultant application); $L \operatorname{tg} \beta$ is the value of the excentricity of the resultant application point (oscillation amplitude).

$$
Q=M_{p} \omega^{2} \operatorname{Ltg} \beta
$$

Comparing expressions (4) and (6) we will get:

$$
M_{p}=\frac{1}{L}\left(\frac{1}{2} q_{1} l_{1}^{2}+\frac{1}{2} q_{2}\left(l^{2}-l_{1}^{2}\right)+M l\right)
$$

When using the concept of reduced mass, calculations are simplified, as the multiplier $\omega^{2} \operatorname{tg} \beta$ can be ignored in the expressions (4) and (5).

The circuits of distributed masses presented in Figure 4 cover almost all possible subpossibilities of unbalanced elements at the body of a vibration exciter.

In the case when the exciter body oscillates with the constant amplitude (plane-parallel vibration exciter), calculation of centrifugal force and the point of its application is as follows:

- the unbalanced mass $m$ of the vibration exciter and the position of its center of gravity - distance $L$ - from the end face of the body - is determined with known methods;

- the resultant of centrifugal force is calculated by the formula $Q=m e \omega^{2}$, where $e$ is the magnitude of the crank eccentricity (oscillation amplitude); is the angular rate of rotation of the drive crankshaft of the vibration exciter.

\section{Calculations by Item 2 .}

The design author has the right to determine locations of correction planes (location of counterweights) in each case depending on the task of vibration exciter designing.
In this sense, the task of dynamic balancing is a creative task for the designer in terms of rational designing of vibration exciters.

Design diagrams of dynamic balancing of vibration exciters that are relevant to schemes in Figures 2a, b, c, d are shown in Figures $7 a, b, c, d$.

The concept of design diagrams is as follows. The main beam (bearing drive crankshaft of the vibration exciter) pictured as a bottom line rests on support 1 (main bearings). There is auxiliary bar $A$ (vibration exciter body, unbalanced mass) shown as a top line, which rests on support 2 (connecting rod bearings).

Centrifugal loads occurring due to unbalanced masses (from the vibration exciter body) during rotation of the bearing drive shaft are depicted in the form of the resultant $Q$, $R, R_{3}, R_{4}$ are centrifugal loads from connecting rod bearing assemblies.

$R_{1}, R_{2}$ are centrifugal loads in connecting rod bearings appearing from the centrifugal force $Q$.

$P, P_{1}, P_{2}$ are counterbalancing forces (centrifugal forces generated during rotation of counterweights mounted on the drive shaft). Geometrical dimensions $L_{i}$ establish connection between the acting forces.

The magnitude of forces $P, P_{1}, P_{2}$ and distances $L_{3}$, $L_{4}$ determining the location of counterweights are to be estimated.

The procedure of calculations is the following:

1. the layout of counterweights (a counterweight) is determined in terms of design;

2. centrifugal loads $R_{1}, R_{2}$ in connecting rod bearings caused by the centrifugal force $Q$ are defined with static methods;

3. the centrifugal forces $R, R_{3}, R_{4}$ arising from oscillation of rod bearing assemblies are determined by the formula: $R_{i}=m_{i} e_{i} \omega^{2}$, where $m_{i}$ is the weight of the bearing assembly; $e_{i}$ is the value of the sleeve excentricity;

4. all above stated forces are summarized taking into account the sign of forces direction;

5. all necessary values of centrifugal forces gained by counterweights are calculated in accordance with conditions of the statics in order to determine dynamic balancing and installation location of counterweights;

6. geometrical dimensions of counterweights (a counterweight) are selected and their (its) weight is determined; these inputs will provide the target centrifugal force.

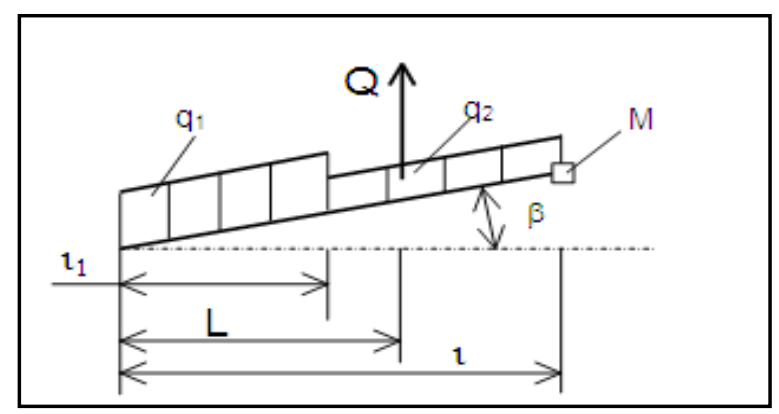

Figure 6. Design model 

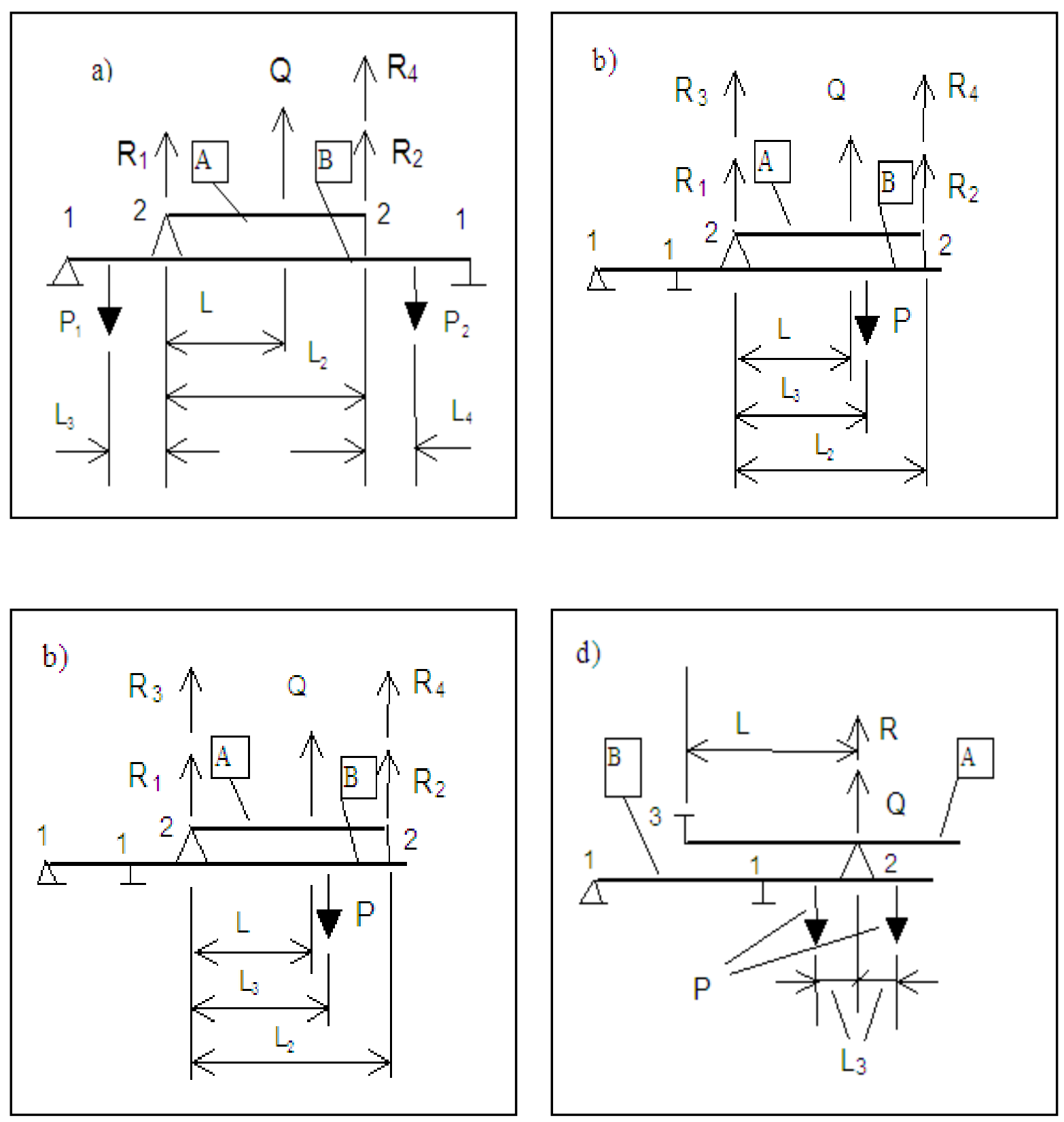

Figure 7. Design diagrams of dynamic balancing 


$$
P=m^{*} y \omega^{2}
$$

where $m$ is the balance weight; $y$ is the distance from the center of gravity of the counterweight to the rotation axis; $\omega$ is the angular rate of rotation of the vibration exciter shaft.

Dynamic balancing (balance of the vibration exciter) for the above stated examples is carried out under the following conditions:

$\sum P_{i}=0 ; \quad \sum M_{i}=0$
a) $P_{1}=R_{1} ; P_{2}=R_{2}+R_{4}$$$
P_{1} L_{3}=P_{2} L_{4}
$$
b) $P=R_{1}+R_{2}+R_{3}+R_{4}$;
$P L_{3}=\left(R_{2}+R_{4}\right) L_{2}$

C) $P_{1}=1 / 2\left(R_{1}-R_{3}\right), R_{1}>R_{3}$ symmetrical arrangement of

$$
P_{2}=1 / 2\left(R_{2}+R_{4}\right) \quad \text { counterweights }
$$

$-P_{1}=1 / 2\left(R_{1}-R_{3}\right), R_{3}>R_{1}$ symmetrical arrangement of

$$
P_{2}=1 / 2\left(R_{2}+R_{4}\right) \text { counterweights (reverse direction) }
$$

d) The design involves one connecting rod bearing which is installed at the point of application of the resultant of centrifugal forces.

$$
P=1 / 2(Q+R)
$$
symmetrical arrangement of counterweights

If a geometric shape of the counterweight corresponds to the one showed in Figure 8 then the main design parameters are determined by the following formulas:

$$
y=\frac{2}{3 \pi} \frac{D^{2}+D d+d^{2}}{D+d} ; F=\frac{\pi\left(D^{2}-d^{2}\right)}{8} ; \delta=\frac{m^{*}}{F \rho}
$$

where $F$ is the cross-section area of the counterweight.

The required thickness of the counterweight is calculated on the basis of the outer and inside diameter of counterweights.

If unsatisfactory results are received in terms of the layout of counteweights on the vibration exciter body (assuming the impossibility of design arrangement), compensation planes or the design of the vibration exciter body is changed and the calculation is repeated. In this sense, the tasks of designing are expressed in successive approximations to obtain the desired results.

When developing the manufacturing of vibration activators, it is recommended that oscillating parts of a test article are weighed and compared with target inputs. In case of divergence between target and actual weights by more than $2 \%$, the weight of the counterweight (counterweights) should be specified.

\section{Conclusions}

Methods of designing of vibration activators are developed on the basis of balanced excentric vibration exciters that meet the requirements of durability of their operational life and their reliability. They can be used in the design of mixers, feeders and other processing equipment in order to increase intensity and effectiveness of their work. The publications (Kuzmichev, 2013; Romanovskiy, 2010; Serebrennikov and Kuzmichev, 1999; Kuzmichev and Lyalinov, 2015) present results of use of vibration activators in mixing processes for building materials.

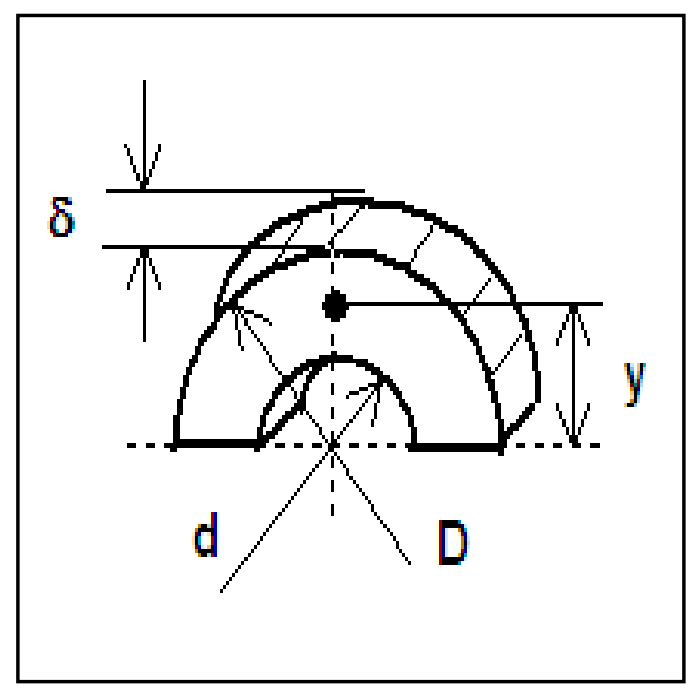

Figure 8. Counterweight. $d$ is the outer diameter, $D$ is the inside diameter, $\delta$ is thickness, and $y$ is the center of gravity. 


\section{References}

Banfill, P.F.G., Teixeira, M.A.O.M., Craik, R.J.M. (2011). Rheology and vibration of fresh concrete: Predicting the radius of action of poker vibrators from wave propagation. Cement and Concrete Research, 41(9), pp. 932-941.

Bauman, V.A., Bykhovskiy, I.I. (1977). Vibratsionnye mashiny $i$ protsessy $v$ stroitel'stve [Vibration machines and construction procedures]. Moscow: Vysshaya Shkola [Higher school], p.256. (in Russian)

Belokobyl'skiy, S.V., Kashuba, V.B., Sitov, I.S. (2008). Povyshenie prochnostnykh kharakteristik betonnogo izdeliia obrabotkoi ego poverkhnosti vysokochastotnym rabochim organom betonootdelochnoi mashiny [Increase of strength characteristics of concrete product by treating its surface with the help of a high-frequency working body of a concrete finisher]. Vestnik mashinostroeniya [Engineering Bulletin], 1, pp. 83-85. (in Russian)

Blekhman, I.I. (1994). Vibratsionnaya mekhanika [Vibration mechanics]. Moscow: Fizmatlit Publishing House, p.400. (in Russian)

Chelomey, V.N. (1981a). Vibratsiya v tekhnike. Spravochnik v 6 tomakh [Machinery vibrations. Reference book in 6 volumes]. Moscow: Mashinostroenie Publishing House, vol. 4, 456 p. (in Russian)

Chelomey, V.N. (1981b). Vibratsiya v tekhnike. Spravochnik v 6 tomakh [Machinery vibrations. Reference book in 6 volumes]. Moscow: Mashinostroenie Publishing House, vol.6, 509 p. (in Russian)

Den-Gartog, Dzh.P. (1960). Mekhanicheskie kolebaniya [Mechanical oscillations]. Moscow: State Publishing Company of Physics and Mathematics Literature, p.600. (in Russian)

Efremov, I.M., Lobanov, D.V. (2008). Novye rotornye smesiteli s razlichnymi sistemami vibrovozbuzhdeniya [New rotary mixing devices with various systems of vibration activation]. Stroitel'nye i dorozhnye mashiny [Construction and road machinery], 9, pp. 7-9. (in Russian)

Efremov, I.M., Lobanov, D.V. (2009). Vibrobetonosmesiteli: put' dlinoy v 70 let [Vibration concrete finishers: 70 years old experience]. Stroitel'nye $i$ dorozhnye mashiny [Construction and road machinery], 10, pp. 15-19. (in Russian)

Efremov, I.M., Lobanov, D.V., Figura, N.V. (2011a). Sovremennye tekhnologii intensifikatsii protsessov peremeshivaniya betonnykh smesey [Modern technologies of stimulation of concrete mixing]. Stroitel'nye $i$ dorozhnye mashiny [Construction and road machinery], 1, pp. 37-41. (in Russian)

Efremov, I.M., Lobanov, D.V., Figura, N.V. (2011b). Mekhanicheskaya aktivatsiya betonnykh smesey pri intensifikatsii protsessov [Mechanical activation of concrete mixes during process stimulation]. Mekhanizatsiya stroitel'stva [Construction mechanizing], 2, pp. 6-8. (in Russian)

Emel'yanova, I.A., Gordienko, A.T., Blazhko, V.V., Anishchenko, A.I. (2009). Betonosmesiteli prinuditel'nogo deystviya s novym printsipom peremeshivaniya komponentov stroitel'nykh smesey [Forced concrete finishers with a new principle of components mixing for construction concrete]. Naukoviy visnik budivnitstva. [Scientific Bulletin on Construction], 54, pp. 190-195. (in Russian)

Kuzmichev V., Lyalinov, A. (2015). Theory and Practice of Functioning Machines for Vibratory Agitation. Applied Mechanics and Materials, 725-726, pp. 590-595. DOI: 10.4028/www.scientific.net/AMM.725-726.590

Kuzmichev, V.A. (2013). Osnovy proektirovaniya vibromikserov [Basics of designing of vibration mixers]. LAP LAMBERT AcademicPublishing, p.136. (in Russian)

Romanovskiy, V.N. (2010). Povyshenie effektivnosti montazhnoy podlivki massivnogo obrudovaniya za schet dopolnitel'nogo vibratsionnogo vozdeystviya na betonnuyu smes' [Improving the efficiency of installation grouting at the expense of additional vibration impact on concrete mix]. SPb: SPSUACE, pp.212-214. (in Russian)

Serebrennikov, A.A., Kuzmichev, V.A. (1999). Vibratsionnye smesiteli (konstruktsii, issledovaniya, raschety) [Vibration mixers (design, study and calculations)]. Moscow: Nedra, p.148. (in Russian)

Verstov, V.V., Tishkin, D.D., Romanovskiy, V.N. (2013). Sovershenstvovanie tekhnologii bespodkladochnogo montazha promyshlennogo oborudovaniya [Improvements of unpadded mounting technologies for industrial equipment]. Montazhnye $i$ spetsial'nye raboty $v$ stroitel'stve [Installation and specialized operations in construction], 7, pp. 27-31. (in Russian) 